\title{
MODEL PEMBELAJARAN HINDU DALAM ADI PARWA
}

\author{
I Wayan Suarjaya \\ Institut Hindu Dharma Negeri Denpasar \\ wayansuarjayaihdn@gmail.com
}

\begin{abstract}
Riwayat Jurnal
Artikel diterima : -

Artikel direvisi : -

Artikel disetujui : -
\end{abstract}

\begin{abstract}
Abstrak
Model Pembelajaran Hindu di Adiparwa, berisi kombinasi model-model Pembelajaran Modern, dikombinasikan dengan aliran Ceritra di Adiparwa. Ada empat model pembelajaran, yaitu 1). Logika teoritis rasional. 2) .Rasional 3). Perilaku 4). Lingkungan belajar. Model pembelajaran ini dipadukan dengan makna Learning in Adiparwa, ceritanya adalah Bhagawan Domya, Bhagawan Drona dan cerita yang terkait dengan model pembelajaran.

Kata kunci: Model Pembelajaran dan Adhiparwa
\end{abstract}

\section{Pendahuluan}

Pengertian Model

pembelajaran menurut Hindu adalah suatu

perencanaan atau suatu pola yang digunakan sebagai pedoman dalam merencanakan pembelajaran di kelas, dapat jugas mengambil contoh contoh model pembelajarqan dari kisah Maha Baratha maupun dari Ramayana. Model pembelajaran dalam dunia modern mengacu pada pendekatan pembelajaran yang akan digunakan, termasuk di dalamnya tujuan-tujuan pengajaran, tahap-tahap dalam kegiatan pembelajaran, lingkungan pembelajaran, dan pengelolaan kelas (Arends dalam Trianto, 2010: 51).

Model pembelajaran adalah kerangka konseptual yang melukiskan prosedur yang sistematis dalam mengorganisasikan pengalaman belajar untuk mencapai tujuan pembelajaran tertentu.Model Pembelajaran memiliki fungsi sebagai pedoman bagi para perancang pembelajaran dan para pengajar dalam merencanakan dan melaksanakan aktifitas belajar mengajar. Berdasarkan pendapat di atas, maka dapat dikatakan 
bahwa model pembelajaran adalah kerangka konseptual yang melukiskan prosedur sistematik dalam mengorganisasikan pengalaman belajar untuk mencapai tujuan pembelajaran tertentu. Model pembelajaran berfungsi sebagi pedoman bagi perancang pembelajaran dan para guru dalam merancang dan melaksanakan proses belajar mengajar.

Fungsi model pembelajaran adalah sebagai pedoman bagi perancang pengajar dan para guru dalam melaksanakan pembelajaran. Untuk memilih model ini sangat dipengaruhi oleh sifat dari materi yang akan diajarkan. Model pembelajaran dipengaruhi oleh tujuan yang akan dicapai dalam pengajaran tersebut serta tingkat kemampuan peserta didik.Menurut Sastra Hindu baik dalam iti hasa dan purana banyak model pembelajarqan Hindu, jika dikaji secara cermat, setiap model pembelajaran juga mempunyai tahaptahap (sintaks) yang dapat dilakukan siswa dengan bimbingan guru. Mari coba menganalisis Model Pembelajaran dalam Adiparwa.

\section{Pembahasan}

\subsection{Model Pembelajaran}

Model pembelajaran menurut Adiparwa mempunyai empat ciri khusus yang tidak dimiliki oleh strategi, metode, atau prosedur model pembelajaran. Selalu dimulai dengan langkah ceritra yang terkandung di dalam alur ceritra Adiparwa. Ciri-ciri khusus model pembelajaran ini adalah:

\subsubsection{Rasional teoretis logis.}

Rasional teoretis logis yang disusun oleh para pencipta atau pengembangnya. Model pembelajaran mempunyai teori berfikir yang masuk akal. Maksudnya para pencipta atau pengembang membuat teori dengan mempertimbangkan teorinya dengan kenyataan sebenarnya serta tidak secara fiktif dalam menciptakan dan mengembangankannya. Kisah ini dapat diambil model pembelajaran yang dilakukan oleh Bhagawan Domya kepada murid - muridnya, Sang Arunika, Sang Utamanyu, Sang Weda masing - masing diberikan tugas yang berbeda yakni;

Sang Arunika sebagai akhli pertanian, diceritrakan bahwa dia ditugasi bersawah adapun kutipan lengkapnya sebagai berikut;

Sedeng ahayu tuwuh nikang wija, teka kang wah saha wrstipata hudan adres. Alah ta galeng nikang sawah. Saka ri wedi niran 
kahibekane toya ikang pari, tinambak nira ta yapwan asowe ikang we alah teka tanbak nika. Muwah tinambak nira. Tan wring deya hira, I wekas antinambakaken tawak nireng we manglendo, tarmolah irikang rahina wengi. Katon tawak nira ngkaneng sawah de sang guru. Mojar Bhagawan Dhomya ri sira, kinon ta ya sirawungwa

Terjemahannya;

Ketika padinya sedang tumbuh denghan baik, datanglah air bah hujan pun turun dengan deras. Karena khawatir, kalau padinyaq tygergenang air. Ditahannyalah air itu, tidak lama antaranya, pematang jebol, ditahan putus lgi, demikian berulang kali. Sang Arunika tiada berdaya lagi, akhirnya badannya dipergunakan untuk menahan air direbahkan dirinya tidak bergerak dari tempatnya itu siding dan malam. Terlihatlah oleh Sang Guru akan keadaan itu seru Bhagawan Dhomya kepadanya lalu ia disuruh bangun ( Zoetmulder 2006: 16 )

Berdasarkan kajian Adiparwa

Rasional teoretis logis selanjutnya

Bhagwan Domya mendidik berdasarkan

Rarional, bahwa anak didik dikembangkan sesuai dengan kemampuan anak didik, seperti Sang Utamanya dididik sebagai akhli peternakan, dididik menjadi anak yang jujur tidak mengambil bukan miliknya seperti kutipan berikut ini;

Mankana ling nira mpu guru. Manêmbah ta sang Utamanyu, umupaksamākên I sila nirān salah. Ikang sakatambay eñjing, lumampah ta sirāhwan, sumêlang manasi muwah. Solih nirānasi, ya ta pawwat nire dang hyang guru. Huwus nirāwwat tasyan, manasi ta sira muwah, pinakopajīwa nirāhwan ikang lêmbu. Katinghalan ta sirānasi ping rwa, inuhutan ta sira de sang guru, apan lobha ngaran ing mangkana; ndātan panasi ping rwa pinakopajīwana nira, ling ning guru. Dadi sira minum irikang kșīa tatśeșa ning lêmbwanusu. (Ādiparwa III.5)

Terjemahannya :

Demikianlah kata sang guru, sang Utamanyu menghormat, minta maaf atas perbuatannya yang salah. Keesokan harinya; ia menggembala lagi, diselingi dengan minta-minta. Akan tetapi semua yang diperolehnya diserahkan kepada guru. Sesudah itu minta-minta lagi untuk penghidupannya selama menggembala lembu. Terlihatlah ia minta-minta yang kedua kalinya, lalu dilarang oleh guru, karena yang demikian dianggap lobha; sejak itu tidak minta-minta yang kedua sebagai penghidupannya, menurut perintah guru. Karenanya ia minum air susu sisa anak sapi menyusu induknya. Ketika ditanya oleh guru, mengatakan bahwa yang diminum sisa anak lembu (Zoetmulder, 2006:17-18).

Anak didik yang Lain Sang Weda sebagai akhli pelayan dan juru masak, 
menunjukkan model rasional teoritis logis, seperti kutipan berikut ini;

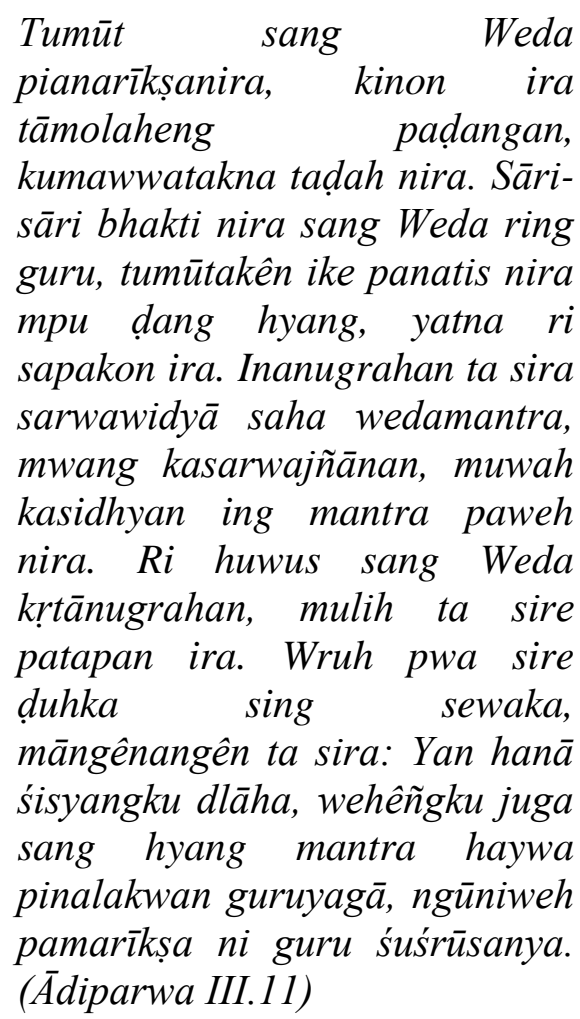

Terjemahannya :

Kemudian sang Weda diujinya. Ia disuruh tinggal di dapur menyediakan hidangan. Serba baiklah persembahan sang Weda kepada gurunya, ia selalu mengikuti jejak gurunya, meski yang buruk-buruk sekalipun, segala perintah gurunya dikerjakan dengan baik. Karenanya ia dianugerahi segala macam ilmu pengetahuan, mantra weda, dan kecerdasan, lagi pula mantra yang sempurna. Sehabis sang Weda menerima anugerah itu, ia pulang ke pertapaannya. Tahulah sekarang akan jerih payah orang yang mengabdi berkatalah dalam hatinya: "Kalau kelak saya mempunyai murid, mantra ini hanya akan saya berikian begitu saja tanpa minta upah ataupun ujian kesetiannya (Zoetmulder, 2006:20-21).

Model Pembelajaran yang diterapkan Bhagawan Dhomya secara tidaksadar telah menjabarkan dalam praktiknya sesuai dengan Model Pembelajaran Rasional teoretis logis, karena mendidik anak sesuai dengan bakat yang logis, sebagai bersawah, beternak dan sebagai pelayan dan tukang masak.

\subsubsection{Landasan pemikiran.}

Landasan pemikiran tentang apa dan bagaimana siswa belajar (tujuan pembelajaran yang akan dicapai). Model pembelajaran mempunyai tujuan yang jelas tentang apa yang akan dicapai, termasuk di dalamnya apa dan bagaimana siswa belajar dengan baik serta cara memecahkan suatu masalah pembelajaran. Bhagawan Domya menitik beratkan siswanya supaya mampu mengatasi masalah yang dihadapi seperti mengatasi masalah pertanian pada saat pertaniannya di serang banjir bandang, yang beternak bagai mana caranya supaya ternaknya berhasil dengan tidak menikmati susu sapi yang mereka pelihara, demikian pula Sang Weda disuruh mengatasi sebagai pelayan yang baik dan tukang masak yang baik Landasan pemikiran yang titerapkan, adalah sikap disiplin, bekerja keras, jujur dan taat kepada perintah guru.

Selain Bhagawan Dhomya mengajarkan anak didiknya supaya mmempunyai landasan pemikiran memiliki karakter; 
1) Sikap disiplin, dalam mengerjakan pekerjaan, disiplin melksanakan perintah guru bekerja keras,

2) Jujur dan taat kepada perintah guru,

3) Sikap hormat kepda Guru Susrusa,

Seperti dalam kutipan berikut:

Guru śuśrusa, bhakti ting guru, guru ngaranya, wang awreddha, tapowreddha, jñānawreddha. Wang awreddha ng sang matuha ring wayah. Kadyanganing, bapa ibu, pangajyan, nginiweh sang sumangaskara rikita, tapowreddha ng sang matuha ring brata jñānawreddha ng sang matuha ring aji.

Terjemahannya :

Guru śuśrusa (berarti) sujud bhakti terhadap guru. Guru namanya orang yang sudah Awreddha, Tapowreddha, dan Jñānawreddha. Orang Awreddha namanya orang yang lanjut usianya sebagai bapak, ibu, orang yang mengajar (pangajyan) lebih-lebih orang yang mentasbihkan (Sumangas-kara) kamu. Tapowreddha sebutannya orang yang lanjut (tua atau matang) dalam brata. Jñānawreddha namanya orang lanjut (tua atau matang) di dalam ilmu pengetahuan (Atmaja, 2012:53).

4) Taat sembahyang kepada Tuhan Yang Maha Esa, karena murid muridnya hidup di Pasraman.Demikian pula halnya ladasan pemikiran Bhagawan Drona mendidik murid - muridnya saat Pandawa dan Korawa masih kecil ditatamkan landasan pemikiran siswanya memiliki karakter sebagai
Satriya; Pañca Satya, yang berarti 5 (lima) jenis kebenaran, yang terdiri dari:

Satya Wacana, setia terhadap perkataan.

(1) Satya Laksana, setia terhadap perbuatan.

(2) Satya Hredaya, setia terhadap hati nurani.

(3) Satya Semaya, setia terhadap janji.

(4) Satya Mitra, setia terhadap teman

3. Tingkah laku.

Tingkah laku mengajar yang diperlukan agar model tersebut dapat dilaksanakan dengan berhasil. Model pembelajaran mempunyai tingkah laku mengajar yang diperlukan sehingga apa yang menjadi cita-cita mengajar selama ini dapat berhasil dalam pelaksanaannya. Adhiparwa menitik beratkan tingka laku yang baik, sepertiBhagaan Domya menitik peradikat pada tingkah laku baik dan benar, terutama mendidik sikap mental dan berbudhi luhur seperti; Kisah Bhagawan Weda menyerahkan pasramannya kepada Sang Utangka, mengawasi semua pasramannya. Tinggal berdua di Pasraman yakni; Sang Utangka bersama istri guru berbulan - bulan lamanya. Pada suatu malam istri Guru meminta kepad Sang Utangka membuat yadnya "Putrot padana" supaya istri guru bisa mempunyai anak. ( Karena kawin dengan Bhagwan Weda tidak 
mempunyai keturunan ) maka senggama dengan istri guru. Karena keteguhan hati Sang Utangka beliau tidak bersedia membuat yadnya putrotpadana( Kasarnya berselingkuh dengan istri Guru ).

Demikian pula halnya Bhagawan Drona mengajar murid muridnya Pandawa da Korawa selalu menitik beratkan sikap dan perilaku yang Pemberani, Jujur, waspada, terpusat pikirannya pada pelajarannya saja. Seperti contoh mengajar muridnya memanah, pikiran harus terpusat kepada yantg akan dipanah, Bhagawa Drono berkata Wahai Arjuna coba bidik burung di pohan kayu, apa yang dilihat ? jika sudah melihat kepala buruh baru dilepas panahnya. Jika masih melihat dahan kayu berarti anda tidak pokus ilmu memanahnya. Ekalawya neniru belajar sendiri seperti itu, kunci dalam belajar harus terpokus pada pelajaran saja pasti berhasil. Kadang - kadang siswa sekarang tidak terpokus pada penjelasan guru di sekolah makanya kurang berhasil dengan baik.

4. Lingkungan belajar.

Lingkungan belajar yang diperlukan agar tujuan pembelajaran itu dapat tercapai. Model pembelajaran mempunyai lingkungan belajar yang kondusif serta nyaman, sehingga suasana belajar dapat menjadi salah satu aspek penunjang apa yang selama ini menjadi tujuan pembelajaran.
Pada akhirnya setiap model pembelajaran memerlukan sistem pengelolaan dan lingkungan belajar yang berbeda. Setiap pendekatan memberikan peran yang berbeda kepada siswa, pada ruang fisik, dan pada sistem sosial kelas. Sifat materi dari sistem syaraf banyak konsep dan informasi-informasi dari teks buku bacaan, materi ajar siswa, di samping itu banyak kegiatan pengamatan gambar-gambar. Tujuan yang akan dicapai meliputi aspek kognitif (produk dan proses) dari kegiatan pemahaman bacaan dan lembar kegiatan siswa. Kisah dalam ceritra Adi Parwa banyak diberikan contoh lingkungan yang baik seperti contoh pendidikan dilaksanakan di Pasraman jauh dari hiruk pikuknya keramaian,seperti dikisahkan dalam ceritran sang Kadru dan Sang Winata. Sang Winata diperbudak Oleh Sang Kadru, karena Sang Winata kalah menebak bulu Kuda Ucaisrawa yang bulunya putih bersih, ternyata kuda itu ada bulu ekornya abu - abu. Oleh karena demikian harus melayani anak - anak Sang Kadru( Sang Naga ) setiap hari. Kemudian Swang Garuda membebaskan ibuknya dari Perbudakan dengan menyerahkan Tirta Amerta kepada 1000 ekor Naga. Sang Garuda berhasil membebaskan ibunya dari perbudakan. Makna yang patut diambil dalam ceritra ini adalah Lingkungan belajar sangat diperlukan terbebas dari tekanan lahir dan batin

\section{Penutup}


Berdasarkan Model Pembelajaran Modern, sebenarnya dalam Purana dan Itihasa terutama dalam Adiparwa, seberarnya sudah tersurat dan tersirat, hanya dibutuhkan kejelian dalam menganalisa. Model Pembelajaran Hindu dalam Adiparwa jika dikaji secara mendalam sudah mencerminkan Model pembelajaran yang baik patut ditiru dan dikemas dengan baik.

1. Rasional teoretis logis.

Rasional teoretis logis yang disusun oleh para pencipta atau pengembangnya. Model pembelajaran mempunyai teori berfikir yang masuk akal. Seperti Pendidikan yang dilakukan oleh Bhagawan Domya dan Bhagawan Drona.

\section{Landasan pemikiran.}

Landasan pemikiran tentang apa dan bagaimana siswa belajar (tujuan pembelajaran yang akan dicapai). Model pembelajaran mempunyai tujuan yang jelas tentang apa yang akan dicapai, termasuk di dalamnya apa dan bagaimana siswa belajar dengan baik serta cara memecahkan suatu masalah pembelajaran, seperti; Sang Utamanyu, Sang Arunika dan Sang Weda.

3. Tingkah laku.
Tingkah laku mengajar yang diperlukan agar model tersebut dapat dilaksanakan dengan berhasil. Model pembelajaran mempunyai tingkah laku mengajar yang diperlukan sehingga apa yang menjadi cita-cita mengajar selama ini dapat berhasil dalam pelaksanaannya. Adhiparwa menitik beratkan tingka laku yang baik, Seperti Sang Utangka dengasn Istri Guru Bhagawan Weda. Demikian pula Bhagawan Drona mengajar Pandawa dan Korawa waktu kecil yang dititik beratkan adalah Tingkah Laku.

4. Lingkungan belajar.

Lingkungan belajar yang diperlukan agar tujuan pembelajaran itu dapat tercapai. Model pembelajaran mempunyai lingkungan belajar yang kondusif serta nyaman, sehingga suasana belajar dapat menjadi salah satu aspek penunjang apa yang selama ini menjadi tujuan pembelajaran. Dalam cerita dikisahkan Sang Kadru dan Sang Winata.

\section{Daftar Pustaka}

Arends, Trianto. 2010. Model Pembelajaran. Bandung

Atmaja, Ida Bagus Oka Punya. 2012. Cilakrama. Denpasar : PHDI Provinsi Bali

Cika, I Wayan. 2006. Kekawin Sabha Parwa Analisi Fililogis. Denpasar : Pustaka Larasan 
Puja, Gede. 1999. Bhagawad Githa. Surabaya : Paramita

Zoetmulder, P. J. 2005. Adiparwa Bahasa

Jawa Kuno dan Indonesia.

Surabaya : Paramita. 